\title{
EDUCAÇÃO AMBIENTAL: caminhos para mudar
}

\author{
Environmental Education: Way for Change
}

\author{
Claudia Regina Bosa \\ Bióloga, M. Sc., Curitiba - PR. e-mail: crbosa@ig.com.br \\ Juan Ramon Soto Franco \\ Técnico da Divisão de Dinamização Cultural do Departamento de Zoológico, Curitiba - PR. \\ e-mail: soto.lira@ig.com.br \\ Marcos Elias Traad da Silva \\ Zootecnista, Dr., Diretor do Departamento de Zoológico de Curitiba - PR. \\ e-mail:traad@onda.com.br \\ Samara Regina Mendes de Moraes \\ Graduanda de Zootecnia, Estagiária do Departamento de Zoológico de Curitiba - PR. \\ e-mail:samarammoraes@yahoo.com.br
}

\section{Resumo}

A Educação Ambiental é um tema que tem sido discutido com mais intensidade desde a década de sessenta. Várias medidas vêm sendo tomadas, desde então, numa tentativa para a promoção do desenvolvimento da sociedade humana com o menor impacto ambiental possível, visando a sustentabilidade e o ecodesenvolvimento. No Brasil, os programas e projetos ambientais executados pela Secretaria Municipal de Meio Ambiente, na Cidade de Curitiba, são destacados pelo seu caráter inovador. A Educação Ambiental, processo informativo e prático que visa ao desenvolvimento crítico e racional das pessoas, quanto às questões ambientais, é uma importante ferramenta para modificar os valores culturais, sociais, políticos e econômicos da população, com a conseqüente melhoria da qualidade de vida. O Departamento de Zoológico de Curitiba iniciou o seu Programa de Educação Ambiental em 1995, objetivando: utilizar o Zoológico como espaço didático, transformando-o em sala de aula aberta e diferenciada; repassar aos visitantes conhecimentos inerentes ao acervo de animais; promover contato direto do visitante com alguns animais; buscar a interdisciplinaridade das áreas de conhecimento e seus conteúdos; valorizar hábitos culturais e cívicos da população, proporcionando o resgate da cidadania. O citado Programa é composto por diversas atividades, que são relatadas neste trabalho.

Palavras-chave: Ecodesenvolvimento; Zooterapia; Zoológico de Curitiba; Preservação Ambiental. 


\section{Abstract}

The environmental Education is a subject that has been intensively discussed since the sixties. Since, many measures has been done, trying to promote the society development with low environmental impact, aiming at the sustainable and the eco-development. The programs and environmental projects conducted by Curitiba's Town Environmental Office, in Brazil, have deserved national and international prominence for its innovative character. The necessity of environmental preservation has today a word-wide concern. The Environmental Education, informative and practical process, that aims at the critical and rational development of the people, related to environmental, is an important tool to modify the cultural, social, political and economical values of the population, leading to one consequent improvement of the life quality. The Curitiba's Zoo Department started in 1991 the Program of Environmental Education with the following objectives: to use the Zoo as a didactic space, transforming it into an open and differentiated classroom; to teach the visiting inherent knowledge of animals; to promote direct contact of the visitor with some animals; to search for the interrelationship of their knowledge areas and contents; to valorize cultural and civic habitats in the population, to provide the rescue of the citizenship. The mentioned Program is composed of different activities that will be treated in this paper.

Keywords: Eco-development; Zoo therapy; Curitiba's Zoo; Environment Preservation.

\section{INTRODUÇÃO}

Através dos tempos, o ser humano sempre tratou das questões ambientais de forma muito confortável, numa escalada extrativista, sem o menor compromisso com as gerações futuras ou com a reposição, na medida em que as reservas naturais abundantes sempre deram suporte aos sistemas de exploração industrial (incluindo-se as minerações e a exploração de petróleo), agrícolas e pecuários. Da mesma forma, a pressão demográfica ao longo da superfície do planeta nunca foi encarada como um problema, mesmo com a evidência remota das fortes tendências de concentração humana no continente asiático, face à sua longa trajetória na história do povoamento "civilizado" do globo terrestre.

A constatação da forte pressão exercida pelos seres humanos ao planeta, basicamente pelos hábitos de consumo cada vez mais elevados - com reflexos diretos no desperdício, verificado com absoluta nitidez nos países do "bloco desenvolvido" - pelas emissões de gases poluentes, na devastação das florestas e no uso indiscriminado de insumos tecnológicos na atividade agropecuária, além do crescimento desordenado dos grandes conglomerados urbanos, têm resultado gradativamente no aumento dos indicadores de poluição da água, do solo e no aquecimento global da terra, com sérias conseqüências ao futuro.

Outro aspecto de suma importância para o ávido avanço do homem sobre os recursos naturais é o elevado nível de competição nos mais variados níveis e instâncias. O mais importante na sociedade moderna, em linhas gerais, é apresentar comportamento competitivo, sem o qual não haverá ingresso no mercado de trabalho e, conseqüentemente, no mercado de consumo. Para ressaltar alguns dos aspectos que regem o comportamento da humanidade em relação à competição, cita-se o contido em Juliatto (2007, p. 13-14):

Parece que, de fato, a competição tomou conta do mundo. Mas, com certeza, a história está apenas repetindo hoje o que sempre aconteceu no passado. Só que, em outros tempos, a competição talvez parecesse mais discreta, menos evidente e ostensiva, menos agressiva. Hoje, ela é generalizada entre países, empresas, pessoas; aparece fora e até mesmo dentro de casa [...] A competição em si, não é nem boa nem má, mas traz boas e más conseqüências. Por um lado, incentiva a emulação entre as pessoas e setores para serem mais criativos, trabalhadores e produtivos. E isso é bom e tem muito a ver 
com educação. Por outro, atitudes como vencer a qualquer custo e notabilizar-se sobre os outros para levar alguma vantagem, reduzem o espaço para a entreajuda e até podem abrir brechas para comportamentos antiéticos. E isso pode ser profundamente deseducativo. Percebe-se hoje no mundo competição demais e cooperação de menos. Com os abundantes e poderosos recursos de que dispomos hoje certamente a situação mundial poderia estar melhor, houvesse mais colaboração entre os povos e nações.

De acordo com Novaes (2007):

As mudanças climáticas estão trazendo secas mais intensas, inundações mais fortes, mais furacões, dificuldades no abastecimento de água - mesmo no Brasil, que é um país privilegiado em matéria de recursos e serviços naturais. Ainda se as emissões de gases que intensificam o efeito estufa continuarem no ritmo atual, no século 21 a temperatura da Terra se elevará entre 2 e 4,5 graus Celsius e o nível dos oceanos subirá entre 18 e 59 centímetros. Um estudo do Banco Mundial alerta que a perda na economia poderá ser de $20 \%$ do produto bruto mundial, cerca de US\$ 8 trilhões. Para enfrentar o problema, será preciso aplicar 1\% do produto bruto mundial, ou US $\$ 400$ bilhões anuais. A Agência Internacional de Energia prevê que serão necessários investimentos de US $\$ 15$ trilhões nos próximos 15 anos em novas fontes de energia.

Em função do exposto, há, entre aqueles que debatem rotineiramente as questões ambientais nos mais variados setores, a aceitação unânime de que a atenuação deste quadro drástico - uma vez que a reversão total parece impossível de acordo com os mais céticos - está na dependência direta da massificação dos processos de disseminação de conhecimentos sobre o meio ambiente, por meio da Educação Ambiental em todos os níveis.

Indicado do jeito que foi no parágrafo anterior, o termo Educação Ambiental parece muito simplório, tendo em vista os graves problemas enfrentados pelos seres vivos do planeta terra. A trajetória da Educação Ambiental, no mundo e no Brasil, remonta esforços que se desdobram desde a década de sessenta. O Programa Nacional de Educação Ambiental (PRONEA), lançado pelo MEC em 1998, é de fato um marco importante na educação brasileira, mas que não é tido como ferramenta concreta, na medida em que é tratado numa proposta de abordagem transversal ao tema na rede de ensino do país.

No entanto, questões centrais sobre a abrangência das ações de Educação Ambiental devem ser transpostas, para que haja efetivo sucesso no convencimento das gerações futuras sobre a necessidade de serem ponderadas com a vida, para que se possa dela usufruir "eternamente".

Como contrapor os interesses meramente econômicos e pessoais com o bem-estar coletivo?

Como elaborar propostas e executar projetos em Educação Ambiental, que se mantenham na memória das pessoas, para que elas consigam mudar de costumes ou que valorizem mais o fato de estarem vivas?

Como aproveitar os espaços mais variados existentes (parques diversos, reservas naturais, praças, zoológicos, fazendas experimentais e de produção, escolas, condomínios urbanos, etc.), para dar a oportunidade de ampla disseminação de conceitos sobre a preservação ambiental e os seus benefícios para a humanidade?

Como inserir definitivamente a Educação Ambiental como matéria obrigatória nos currículos escolares, uma vez que há tantos temas contemporâneos de suma importância que necessitam de tratamento tão especial quanto a Educação Ambiental?

Este artigo apresenta uma contribuição sobre a importância da Educação Ambiental no combate à destruição contínua do planeta. Para tanto, é feita uma abordagem teórica sobre o assunto, bem como são relatadas algumas experiências bem-sucedidas desenvolvidas pelo Departamento de Zoológico da Secretaria Municipal do Meio Ambiente da Prefeitura Municipal de Curitiba. Espera-se que sirva de base para que outras iniciativas sejam elaboradas e oferecidas aos cidadãos, buscando-se criar consciência ecológica às futuras gerações que poderão decidir sobre o seu próprio rumo. O ser humano que tem sido capaz de destruir, também deve ter a capacidade para remediar. 


\section{Agressões ao meio ambiente}

[...] Aprender a ler e interpretar a natureza e desenvolver capacidade de interferir nos ecossistemas de forma sustentável, torna-se componente estratégico fundamental de ação cidadã e planetária. A conscientização é básica para a tomada de decisões sustentáveis para as espécies e o planeta. (BRASIL, 2006, p. 94).

Os seres vivos que habitam a terra, ditos como bióticos, formam, com os recursos abióticos do planeta, um complexo que interage de forma sistêmica, indicando uma ligação das causas com os seus efeitos, o que pode demonstrar que, para remediar ou mitigar impactos causados pela interferência direta nestes sistemas, as suas inter-relações também devem ser consideradas. A má utilização dos recursos do planeta, a derrubada das florestas para a retirada da madeira ou para a introdução de monoculturas agrícolas contínuas têm sido os focos principais dos noticiários sobre a devastação ambiental, principalmente a partir da constatação do aquecimento global.

Gradativamente, o efeito do aquecimento contínuo da terra é verificado sob diferentes aspectos, mas a real devastação é de fato mais entendida pelos seres humanos quando há evidências do desaparecimento de animais e vegetais numa escalada jamais vista, uma vez que avançam os estudos sobre as espécies ameaçadas de extinção.

A intensidade e velocidade com as quais as notícias sobre a devastação da terra chegam aos lares do mundo, graças à interação com as mídias em geral, mostram a redução das áreas florestadas, a destruição das matas ciliares, o aumento da erosão e da desertificação, a ação cada vez mais intensiva de fenômenos atmosféricos diversos (chuvas excessivas, furacões, mudanças climáticas). Segundo Muraro (2006), mais de 516 milhões de hectares são afetados pela desertificação na América Latina, causando a perda de 2 bilhões de toneladas de camada de solo arável por ano.

Fernandez (2004) relata o "efeito de borda", em que uma pequena mata passa a estar cercada por áreas abertas, no qual uma série de alterações microclimáticas começa a ocorrer na periferia do fragmento residual da floresta, promovendo a sua morte de fora para dentro. Isso indica que invariavelmente a derrubada da floresta implica no seu gradativo processo de desaparecimento.

De certa forma, os sinais de alerta sobre os habitantes do planeta têm surtido efeito, tanto é que, nos últimos dez anos, as denúncias sobre agressões ambientais têm aumentado, indicando que há indignação e fundamentalmente medo sobre as conseqüências no futuro.

\section{Alguns marcos históricos importantes sobre educação ambiental}

A trajetória da Educação Ambiental, no mundo e no Brasil, remonta esforços que se desdobram desde a década de 1960. Naquela época, o mundo refletia sobre o futuro do planeta e da civilização, na medida em que os prejuízos causados pela emissão das bombas atômicas de Hiroshima e Nagasaki, em 1945, durante a Segunda Guerra Mundial, acarretaram debates, reflexões e, sobretudo, polêmica.

Diversos fatos sucederam na história contemporânea chamando mais uma vez a atenção de todos, dirigentes políticos, pesquisadores, educadores e população em geral, sobre a necessidade de se avaliar a construção de valores éticos sociais, visando à sobrevivência da vida no planeta e, em especial, a vida humana (CASCINO, 1999).

Em 1968, a Reunião do Clube de Roma, agregando os sete países mais ricos do mundo, discutiu o crescimento econômico e seus impactos sobre a natureza e sobre a sociedade. Dessa reunião, surgiu o documento The Limits of Growth, cujo conteúdo alertava a todos os países membros da ONU sobre a necessidade de planejar o progresso de modo compatível às leis da ecologia, tendo então originado o termo ecodesenvolvimento. O mesmo documento alertava sobre a urgência de uma educação multidisciplinar, visando ao mesmo objetivo, em todos os níveis da educação formal. Em Estocolmo (1972), a educação visando ao ecodesenvolvimento foi exaustivamente trabalhada, sem que, no entanto, as conclusões tomassem um rumo multidisciplinar. 
Em Belgrado (1975), a chamada educação multidisciplinar foi mais entendida como Educação Cidadã ou visando a Cidadania (CAZAPSKI, 1998). Com esse foco, a Educação Ambiental passou a ser recomendada pelo Programa Internacional de Educação Ambiental (PIEA), para formular seus princípios orientadores, já que havia a necessidade de se fundamentar as bases políticas que norteariam a então Educação Interdisciplinar. A partir desse substrato, em Tbilisi, em 1977, concluiu-se que:

A Educação Ambiental é um processo continuado e deve abranger pessoas de todas as idades e todos os níveis, no âmbito do ensino formal e não formal. Os meios de comunicação social têm a grande responsabilidade de colocar seus enormes recursos a serviço dessa enorme missão educativa. Os especialistas no assunto, e também aqueles cujas ações e decisões podem repercutir significativamente no meio ambiente, deverão receber, no decorrer da sua formação, os conhecimentos e atitudes necessários, além de detectarem plenamente o sentido de suas responsabilidades nesse aspecto. Uma vez compreendida devidamente, a educação ambiental deve constituir um ensino geral e permanente, reagindo às mudanças que se produzem num mundo em rápida evolução. Esse tipo de educação, deve também possibilitar ao indivíduo compreender os principais problemas do mundo contemporâneo, proporcionandolhe conhecimentos técnicos e as qualidades necessárias para desempenhar uma função produtiva, visando à melhoria da qualidade de vida e à proteção do meio ambiente, atendendo-se aos valores éticos. Ao adotar um enfoque global, fundamentado numa ampla base interdisciplinar, a educação ambiental torna a criar uma perspectiva geral, dentro da qual se reconhece existir uma profunda interdependência entre o meio natural e o meio artificial. Essa educação contribui para que se exija a continuidade permanente que vincula os atos do presente às conseqüências do futuro; além disso, demonstra a interdependência entre as comunidades nacionais e a necessária solidariedade entre todo o gênero humano. (DIAS, 1988, p. 42).

A Educação Ambiental deve ser dirigida à comunidade, despertando o interesse do indivíduo em participar de um processo ativo para resolver os problemas dentro de um contexto de realidades específicas, estimulando a iniciativa, o senso de responsabilidade e o esforço para construir um futuro melhor. Por sua própria natureza, a educação ambiental pode, ainda, contribuir satisfatoriamente para a renovação do processo educativo. Visando a atingir esses objetivos, a educação ambiental exige a realização de certas atividades específicas, de modo a preencher as lacunas que ainda existem em nossos sistemas de ensino, apesar de todas tentativas feitas até então.

Conseqüentemente, a Conferência de Tbilisi (1) CONVOCA todos os Estados-Membros da ONU a incluir, em suas políticas de educação, medidas visando a incorporar ao conteúdo dos programas de aprendizagem diretrizes e atividades ligadas ao meio ambiente, com base nos objetivos e características já mencionadas; (2) CONVIDA as autoridades educacionais a intensificar seu trabalho de reflexão, pesquisa e inovação no que tange à educação ambiental; (3) INCENTIVA os Estados-Membros a colaborar nessa área, principalmente através do intercâmbio de experiências, pesquisas, documentação e materiais, colocando, além disso, os serviços de formação à disposição do corpo docente e dos especialistas de outros países, e finalmente, (4) ESTIMULA a comunidade internacional a dar uma generosa ajuda para fortalecer essa colaboração numa área de atuação que simboliza a necessária solidariedade de todos os povos, e que pode considerar-se como particularmente alentadora na promoção do entendimento internacional, e da causa da paz (IBAMA, 1997).

As postulações e recomendações de Tbilisi fundamentaram todo processo de Educação Ambiental no Brasil e no Mundo. Mas ainda restavam algumas reflexões fundamentais sobre os efeitos do progresso sobre a Biodiversidade e sobre as Mudanças Climáticas. Desse modo, a ONU consagrou estes dois temas, em 1988, como pauta para ser discutida no Grande Encontro Mundial ocorrido em 1992, na cidade do Rio de Janeiro, mais conhecida como Eco92. Em 1988, a ONU entendeu a importância de se produzir documentos que refletissem as intenções dos Estados-Membros, quanto ao futuro do planeta 
e da humanidade. Tais documentos, certamente, seriam gerados a partir das discussões sobre a Convenção da Biodiversidade e da Convenção sobre as Mudanças Climáticas. Assim, como resultado da Eco92, surgiram $A$ Carta da Terra e a Agenda 21, posto que os trabalhos da Comissão Brundtland, realizados de 1977 a 1983, recomendavam que ações em comum deveriam ser tomadas até o início do Século XXI, em prol do desenvolvimento sustentável. Foi assim que, no Brasil, os esforços mais expressivos passaram a se consolidar para dar forma e estrutura ao sistema geral relativo ao meio ambiente, e mais ainda, para dar substância e ênfase ao processo de Educação Ambiental.

Atualmente, a Educação Ambiental no Brasil, com suas bases definidas em Tbilisi, conta com o Programa Nacional de Educação Ambiental (Pronea), lançado pelo Ministério da Educação e Cultura (MEC), em 1998. Além disso, foi necessário que cada país elaborasse a sua Agenda 21 e, posteriormente, as Agendas 21 Estaduais, Regionais e Municipais, objetivando-se localizar problemas ambientais concretos, além do quadro real de intenções das Unidades Federativas da União; em todas elas, constam capítulos especiais para a Educação Ambiental. Portanto, resultaram como apoio ao Pronea a Agenda 21 e o incentivo para a criação de Centros de Educação Ambiental (CEA), que começaram a surgir como centros de referência durante o processo preparatório da Eco92. Para tanto, foram realizados encontros nacionais entre o MEC e os Educadores Ambientais e entre outras partes interessadas; e, por fim, em 1993, o MEC formalizou a implantação dos CEA como instrumentos complementares do processo de mudança na formação integral do cidadão, diante da nova consciência ambiental, interagindo com diversos níveis e modalidades de ensino e introduzindo práticas de Educação Ambiental junto às comunidades. São, na verdade, pólos de referência e irradiação para as ações regionais. Em 1993, existiam cinco CEA. Em 1997, já eram dezenas de Centros criados por diferentes instituições governamentais ou não-governamentais, como empresas, ONGs, universidades e prefeituras municipais. Em 1998, o Pronea incorporou os CEAs como parte do programa e, portanto, apoiados pelo MEC. Hoje, pode ser um Centro de Educação Ambiental qualquer entidade que esteja disposta a trabalhar com a comunidade. Além disso, a Educação Ambiental, desde 27/04/1999, já conta com legislação própria descrita na Lei Federal n. ${ }^{\circ}$ 9795, consoante aos documentos internacionais, Agenda 21 Federal e Estadual, na qual se incluem os cursos regulares de formação de professores de Educação Ambiental.

\section{Educação ambiental no zoológico de Curitiba}

Diante do panorama apresentado, o Departamento de Zoológico, pertencente à Secretaria Municipal do Meio Ambiente (SMMA), da Prefeitura Municipal de Curitiba, iniciou em 1991 o Programa de Educação Ambiental, com os seguintes objetivos:

a) utilizar o Zoológico como espaço didático, transformando-o em sala de aula aberta e diferenciada;

b) repassar aos visitantes conhecimentos inerentes ao acervo de animais, caracterizando as espécies nativas e as exóticas, bem como indicando aquelas ameaçadas de extinção;

c) promover contato direto do visitante com alguns animais;

d) buscar a interdisciplinaridade das áreas de conhecimento e seus conteúdos;

e) valorizar hábitos culturais e cívicos da população, proporcionando o resgate da cidadania.

\section{Metodologia e equipamentos disponíveis}

O Programa de Educação Ambiental do Departamento de Zoológico de Curitiba é composto por dois locais de atendimento ao público.

\section{Centro de atendimento ao visitante}

É um espaço utilizado para recepcionar o público visitante e repassar, por meio de palestras, vídeos educativos e de sensibilização, informações relacionadas ao melhor roteiro a percorrer durante a visita, conduta que o visitante deve ter durante sua estada no Zoológico, divulgação dos trabalhos 
desenvolvidos na área de educação ambiental, histórico do zoológico, o ecossistema em que está inserido e informações gerais sobre o acervo de animais que este espaço abriga. O referido espaço foi reativado no segundo semestre de 2006 e está localizado ao lado da entrada principal do zoológico, na parte externa.

\section{Centro de educação ambiental}

O Centro de Educação Ambiental é composto por um ambiente aberto ao público, localizado na parte central do zoológico, onde há a oportunidade de conhecer animais taxidermizados de diferentes espécies e partes do corpo, como crânios, bicos, patas e ovos. Os visitantes recebem informações técnicas sobre o acervo em questão, além de ter acesso aos informativos do Zoológico e fichas biológicas, apreciando os trabalhos desenvolvidos com exposições fotográficas, atividades lúdicas e de sensibilização.

Além das informações direcionadas ao público no Centro de Atendimento ao Visitante e no Centro de Educação Ambiental, outras atividades de Educação Ambiental são desenvolvidas pelo Departamento de Zoológico de Curitiba, como forma de ampliar as possibilidades de acesso das mais variadas pessoas que visitam o local.

\section{Visitas educativas}

Trata-se de um atendimento diferenciado às escolas da rede municipal, estadual e particular de ensino, por meio de visitas com acompanhamento de técnicos. A visita educativa tem por objetivo repassar informações sobre as espécies do acervo do zoológico, tais como distribuição geográfica, suas relações com o meio e a importância do Zoológico na conservação das espécies.

A atividade tem início com uma palestra e com atividades de sensibilização no Centro de Atendimento ao Visitante. Em seguida, os visitantes caminham até o Centro de Educação Ambiental. No trajeto, são repassadas informações relacionadas com o ecossistema, onde o zoológico está inserido e informações gerais sobre o acervo de animais.

As escolas interessadas marcam a visita, que acontece de terça a sexta-feira, pela manhã, a partir das 9 horas e à tarde, a partir das $13 \mathrm{~h} 30 \mathrm{~min}$, ao longo de todo o ano letivo. Esta visita é dirigida a turmas de no máximo 40 alunos, desde a segunda série do ensino fundamental, os quais devem vir acompanhados de professores. Visitas orientadas também são realizadas no Museu de História Natural e no Passeio Público (outras duas unidades pertencentes ao Departamento de Zoológico de Curitiba), cada uma delas incluindo informações relacionadas com o acervo animal e com o ecossistema em que estão inseridos.

\section{Acantonamento ecológico}

Esta atividade foi criada em 1991 e atende a uma das necessidades mais emergentes nos dias atuais: a integração do ser humano com a cidade em que vive e com a natureza que o circunda. Desta forma, o Departamento de Zoológico de Curitiba dispõe de uma casa especialmente projetada dentro do Parque Iguaçu, para atender 40 crianças na faixa etária de nove aos doze anos. O local possui: uma trilha interpretativa em meio à mata nativa, pomar, horta, um minizôo de animais domésticos e jardim dos sentidos.

As atividades técnicas, recreativas, lúdicas e de sensibilização são realizadas com crianças da rede municipal de ensino e outras instituições, tendo a duração de um final de semana, inclusive o pernoite, tendo como objetivos gerais:

a) informar e sensibilizar as crianças quanto às questões do meio ambiente para o equilíbrio e sustentação da vida no planeta;

b) buscar a interdisciplinaridade das áreas do conhecimento e conteúdos a serem trabalhados;

c) promover o conhecimento das espécies componentes da fauna e da flora brasileiras, aspectos biológicos e suas relações com o meio. 
Como objetivos específicos, a atividade de Acantonamento Ecológico busca:

a) identificar, nas trilhas interpretativas, os diferentes tipos de animais e vegetais e a importância de sua preservação;

b) proporcionar um contato mais próximo com os animais domésticos, evidenciando suas características e sua utilidade para a vida do ser humano;

c) informar, por meio de palestras, a biologia de animais peçonhentos, as atitudes de preservação e segurança com eles;

d) propiciar o contato direto com a terra, por meio de atividades práticas na horta e no pomar;

e) reconhecer a ação dos agentes poluidores sobre o meio ambiente, os prejuízos por eles causados e as alternativas de controle;

f) valorizar hábitos culturais, cívicos e tradições populares, proporcionando o resgate da cidadania;

g) desenvolver atividades práticas de esporte, lazer, recreação e de sensibilização relacionadas à temática ambiental;

h) informar noções de astronomia, salientando a relação e a influência dos astros sobre o planeta Terra.

\section{Zooterapia}

Atividade realizada em setores de pediatria dos hospitais, asilos e instituições assistenciais de crianças e adultos portadores de necessidades especiais, tendo por objetivo atender a este público que não tem oportunidade de ir até o Zoológico. Consiste em levar a estes locais filhotes de animais domésticos e alguns silvestres de índole pacífica, para que proporcionem, durante algumas horas, divertimento, distração, conforto, relaxamento e alegria a estas pessoas. São utilizados animais como: coelhos, pintos, patos, porcos da índia, hamster, chinchilas, furões, calopsitas, tigres-d'água, jabutis e um filhote de jibóia, entre outros. Dessa forma, os participantes e seus familiares têm a oportunidade de tocar e acariciar estes animais, recebendo informações gerais sobre eles.

\section{O zôo vai à escola}

Mais do que informações e conceitos, a escola deve trabalhar atitudes para a formação de valores, possibilitando, por meio da consolidação de competências diversas, a aprendizagem de habilidades que promovam a educação para a cidadania plena. Este, se não o maior, é um grande desafio para a educação e para os educadores brasileiros, por conseqüência.

Comportamentos adequados em relação ao meio ambiente são assimilados na prática cotidiana da escola: gestos de solidariedade, hábitos de higiene pessoal e dos diversos ambientes, participação ética em pequenas negociações podem ser exemplos disso, com projetos de Educação Ambiental.

O Projeto Zôo vai à Escola fundamenta-se nesta visão e aposta nos alunos da Rede Municipal de Ensino de Curitiba como importantes multiplicadores da consciência ambiental. Acredita-se que estando sensibilizados, os futuros plenos cidadãos perceberão a importância da preservação dos ecossistemas para a sua existência e para o convívio harmonioso com os recursos naturais como um todo. O desenvolvimento do referido projeto se dá nas Escolas Municipais, por meio de exposições itinerantes de animais taxidermizados e partes dos corpos dos animais, como: patas, bicos, crânios, ovos, entre outros. Ao mesmo tempo, são ministradas palestras sobre recursos naturais renováveis e não-renováveis e atividades lúdico-recreativas e de sensibilização, com profissionais de uma equipe com formação multidisciplinar.

Os objetivos gerais do Projeto O Zôo vai à Escola são:

a) compreender a cidadania como participação social e política;

b) perceber-se como integrante, dependente e agente transformador do ambiente, identificando seus elementos e interações entre eles. 
Os objetivos específicos do Projeto O Zôo vai à Escola são:

a) entender o conceito de recurso natural;

b) compreender a importância da preservação do recurso natural água;

c) propiciar o contato com animais taxidermizados da fauna brasileira e principais ecossistemas mundiais;

d) perceber a importância de preservar os ambientes naturais.

\section{Uma noite no zôo}

Esta atividade ocorre quinzenalmente e tem por objetivo despertar a consciência ambiental em jovens e adultos. Os participantes deste programa são prioritariamente pessoas que não concluíram o ensino fundamental e estão matriculados na E.J.A. (Educação de Jovens e Adultos). Como o Programa de Educação Ambiental do Zoológico de Curitiba não possuía atividades para atender a este público, no ano de 2006 surgiu esta idéia, para suprir as carências deste público, que apresenta disponibilidade para realização de atividades somente no período noturno. A atividade também é ofertada para alunos de graduação em áreas afins. No programa "Uma noite no Zôo" são realizadas palestras sobre animais peçonhentos e segurança na mata, cerimonial do fogo, onde é discutida a importância do fogo para a natureza e para a sociedade humana e, para finalizar, é realizada uma visita noturna ao zoológico, sendo possível fazer a observação do comportamento dos animais.

\section{Oficina ambiental}

Atividade dirigida aos alunos da Educação Infantil e da primeira etapa do Ensino Fundamental de escolas municipais e particulares. O programa é realizado no espaço da Casa de Acantonamento, no período das 9 h00 às $17 \mathrm{~h} 00$, às terças-feiras. Os alunos, em número máximo de 40, participam de atividades lúdicas e recreativas, conhecendo as características dos animais silvestres, exóticos e nativos, e de alguns animais domésticos, podendo manuseá-los. Participam em atividades práticas de horta e pomar, onde conhecem as propriedades e benefícios das frutas e verduras. Ainda, são desenvolvidas atividades de culinária, onde os próprios alunos têm a oportunidade de fazer sucos, incentivando, assim, a alimentação saudável. Esta atividade vem ao encontro dos conteúdos trabalhados nas fases iniciais do ensino fundamental, complementando o trabalho do professor em sala de aula.

\section{Trilha interpretativa}

Realizada em um ecossistema de Floresta com Araucária, pertencente à área da Casa de Acantonamento, busca divulgar as características deste ambiente, sensibilizando para a sua importância e necessidade de preservação. São abordados vários conteúdos, como: flora, fauna, plantas parasitas, plantas epífitas, relações entre plantas e animais, entre outros. Ainda são realizadas atividades lúdicas como a trilha sensitiva, onde os participantes utilizam todos os sentidos, menos a visão para andar no interior da mata. A atividade é ofertada para grupos de no máximo 40 alunos a partir da terceira série do Ensino Fundamental.

\section{Teatro na escola}

Esta atividade teve início em 2002 na modalidade de teatro de fantoches, tendo, a partir de abril de 2004, sido introduzida na modalidade teatro vivo, quando os técnicos da equipe de Educação Ambiental do Zoológico Municipal de Curitiba trabalham como atores. Nas duas modalidades, os temas das peças trazem histórias sobre o tráfico de animais silvestres, preservação das espécies e respeito à natureza. Os teatros são realizados em escolas municipais, estaduais e particulares, priorizando as primeiras etapas do ensino fundamental. Ainda são realizadas apresentações em eventos como o Festival da Primavera, realizado todos os anos no Passeio Público de Curitiba. 


\section{Alguns resultados}

Desde a implantação do Programa de Educação Ambiental do Zoológico Municipal de Curitiba em 1991 até a presente data, milhares de pessoas foram atendidas e a demanda vem sendo cada vez maior. Pode-se observar, na Tabela 1, os atendimentos realizados ao longo dos anos nos vários programas desenvolvidos.

Tabela 1 - Total de participantes e instituições atendidas pelos projetos do Programa de Educação Ambiental do Zoológico Municipal de Curitiba (1995 a 2005) Table 1 - Total of participants and institutions attended by Curitiba's Zoo Environmental Education Program (1995 - 2007)

\begin{tabular}{|c|c|c|}
\hline PROGRAMA & PARTICIPANTES & INSTITUICOES \\
\hline Visita educativa & 53.761 & 1.147 \\
\hline Zooterapia & 10.345 & 241 \\
\hline Acantonamento & 14.229 & 365 \\
\hline Oficina ambiental 9 & 2.620 & 82 \\
\hline Zồ vai à escola & 9.281 & 75 \\
\hline Atividades externas (") & 12.795 & 24 \\
\hline Centro de oducação ambiental ${ }^{\mu-\infty}$ & 819.030 & \\
\hline Centro de atendimento ao visitante & 363.518 & \\
\hline TOTAL & 1.287 .752 & 1.959 \\
\hline
\end{tabular}

(*) O Programa teve início em julho de 1999.

$(* *)$ Atividades externas (exposições e palestras técnicas).

(***) O Centro de informação entrou em reforma em abril de 2004 e reabriu em dezembro do mesmo ano como Centro de Educação Ambiental.

Não existe registro dos atendimentos realizados entre os anos de 1991 e 1994.

\section{CONSIDERAÇÕES FINAIS}

A Educação Ambiental é, sem dúvidas, um dos importantes eixos de formação do ser humano. Como tema transversal, é por meio dela que se pode formar cidadãos críticos e conscientes de suas atitudes, pessoas responsáveis e solidárias, que serão capazes de entender e mudar os rumos que nossa civilização está tomando a respeito da relação homem/natureza. E pensando desta forma, uma instituição que tem dado importância e está trabalhando para isso é a Divisão de Dinamização Cultural do Departamento de Zoológico de Curitiba, que vem ampliando cada vez mais seus programas educativos e percebendo, a cada ano, o grande interesse das instituições em participar deles. Esse fato comprova a qualidade, excelência e importância das atividades desenvolvidas na formação de alunos dos mais variados níveis de ensino.

\section{AGRADECIMENTOS}

Agradecemos aos técnicos da Divisão de Dinamização Cultural do Zoológico Municipal de Curitiba: Cristiane Graminho Zeni, Daniele Sandra Purcino e Valdenísio Ferreira dos Santos, peças fundamentais para o andamento de nosso programa de Educação Ambiental e aos colaboradores, como biólogos, veterinários, estagiários, tratadores, pessoal de manutenção, sem os quais o desenvolvimento de nossas atividades seria impossível. 


\section{REFERÊNCIAS}

BRASIL. Órgão Gestor da Política Nacional de Educação Ambiental. Ministério do Meio Ambiente. Ministério da Educação. Juventude, cidadania e meio ambiente: subsídios para elaboração de políticas públicas. Brasília: UNESCO, 2006.

CASCINO, F. Educação ambiental: princípios, história, formação de professores. São Paulo: SENAC, 1999.

CAZPSKI, S. A implantação da educação ambiental no Brasil. Brasília: MEC, 1998.

DIAS, G. F. Educação ambiental: princípios e práticas. 5. ed. São Paulo: Global, 1988.

FERNANDEZ, F. A. S. O poema imperfeito: crônicas de biologia, conservação da natureza e seus heróis. 2. ed. Curitiba: Universidade Federal do Paraná, 2004. 258 p.

IBAMA. Educação ambiental: as grandes orientações da Conferência de Tbilisi. Brasília: IBAMA, 1997. (Série Estudos Educação Ambiental; Edição Especial).

JULIATTO, C. I. Parceiros educadores: estudantes, professores, colaboradores e dirigentes. Curitiba: Champagnat, 2007.

MURARO, R. M. História do meio ambiente. Higienópolis: Zit, 2006. 24 p.

NOVAES, W. Washington Novaes encerra série de aulas magnas no Ipiranga. São Paulo, 2007. Disponível em: <http://www.smarcos.br>. Acesso em: 13 nov. 2007.

Recebido em: 14/05/2007

Received in: 05/14/2007

Aprovado em: 31/07/2007

Approved in: 07/31/2007 